\title{
Modulation of the maternal immune system by the pre-implantation embryo
}

\author{
Caroline G Walker ${ }^{1,2 *}$, Susanne Meier ${ }^{1}$, Mathew D Littlejohn ${ }^{1}$, Klaus Lehnert ${ }^{3}$, John R Roche', Murray D Mitchell ${ }^{2,4}$
}

\begin{abstract}
Background: A large proportion of pregnancy losses occur during the pre-implantation period, when the developing embryo is elongating rapidly and signalling its presence to the maternal system. The molecular mechanisms that prevent luteolysis and support embryo survival within the maternal environment are not well understood. To gain a more complete picture of these molecular events, genome-wide transcriptional profiles of reproductive day 17 endometrial tissue were determined in pregnant and cyclic Holstein-Friesian dairy cattle.

Results: Microarray analyses revealed 1,839 and 1,189 differentially expressed transcripts between pregnant and cyclic animals (with $\geq 1.5$ fold change in expression; P-value $<0.05$, MTC Benjamini-Hochberg) in caruncular and intercaruncular endometrium respectively. Gene ontology and biological pathway analysis of differentially expressed genes revealed enrichment for genes involved in interferon signalling and modulation of the immune response in pregnant animals.

Conclusion: The maternal immune system actively surveys the uterine environment during early pregnancy. The embryo modulates this response inducing the expression of endometrial molecules that suppress the immune response and promote maternal tolerance to the embryo. During this period of local immune suppression, genes of the innate immune response (in particular, antimicrobial genes) may function to protect the uterus against infection.
\end{abstract}

\section{Background}

Over the past three decades, there has been a coincidental decline in fertility associated with genetic selection for increased milk production. It is estimated that approximately $50 \%$ of the potential profitability from genetic selection for milk production is lost due to a reduction in fertility [1].

The fertilisation rate for lactating dairy cattle is around $90 \%$ and does not differ between low-moderate and high-producing animals when managed under pastoral conditions[2]. However, the calving rate in lower producing animals is approximately $55 \%$, whereas for high-producing animals, this rate is approximately $35 \%$ [2]. Pregnancy losses are thought to occur primarily during the pregnancy recognition/pre-implantation period [2], making studies of endometrial gene expression critical to further understanding of pregnancy

\footnotetext{
* Correspondence: Caroline.Walker@dairynz.co.nz

'DairyNZ Ltd., Hamilton, New Zealand

Full list of author information is available at the end of the article
}

establishment, recognition and maintenance within the bovine reproductive cycle.

Successful pregnancy in mammals requires both a viable embryo and a receptive endometrium. Synchronous signalling between the endometrium and embryo during the pre-implantation period is critical for normal embryo development, implantation of the embryo, and placentation [3]. The early embryo is nourished by secretions (histotroph) from the uterine glands (intercaruncular endometrium) and during implantation forms a close physical association (attachment) with the caruncular endometrium [4]. Pregnancy thus represents an immunological contradiction, in that the immunologically foreign embryo is able to form a close physical relationship with the maternal endometrium that lasts throughout pregnancy. Under normal circumstances, a foreign tissue would likely be rejected by the recipient unless the immune system was significantly suppressed or tolerant to the tissue. That the embryo can survive in the presence of the maternal immune system has lead
Ciomed Central 
to the hypothesis that the uterus is an immunologically privileged site [5].

Several mechanisms have been proposed to account for the ability of the embryo to survive in the maternal environment including: antigenic immaturity of the conceptus (the bovine trophoblast, like other mammalian species, does not express classical polymorphic major histocompatibility complex (MHC) class 1 proteins in areas in contact with the maternal endometrium during early pregnancy [5]) and maternal immunological inertness to the conceptus or localised immune tolerance [6].

Local immunosuppression, required for establishment and maintenance of pregnancy, would leave the uterus vulnerable to infection. An increase in innate immune activity may be expected to protect the uterus from infection.

The aim of this study was to identify molecules and pathways involved in pregnancy recognition and maintenance and, in particular to characterise the local immune response that occurs in the endometrium as a consequence of pregnancy. The transcriptional response to the presence of an embryo was characterised during the pre-implantation period in dairy cows. Novel molecules and pathways potentially involved in mechanisms the embryo uses to evade the maternal immune system were identified.

\section{Results}

\section{Differentially expressed genes}

Microarray analyses revealed 1,839 and 1,189 differentially expressed transcripts between pregnant and cyclic animals (with $\geq 1.5$ fold change in expression; P-value < 0.05, MTC Benjamini-Hochberg) in caruncular and intercaruncular endometrium respectively (Additional file 1, Table S1). The majority of transcripts were upregulated in pregnant animals (1027 in caruncular, 633 in intercaruncular). Some genes were differentially expressed between pregnant and cyclic animals in either the caruncular or intercaruncular tissues. Of these, 1027 (480 up-regulated in pregnant) differentially expressed transcripts were identified in caruncular endometrium only, and a further 377 (86 up-regulated in pregnant) differentially expressed transcripts were identified only in intercaruncular tissue (Figure 1).

\section{Molecular and biological function and pathway analysis} Ingenuity pathway analysis (IPA) revealed molecular networks and pathways associated with genes that were differentially expressed in pregnant versus cyclic animals. 1,499 individual genes were contained within the Ingenuity database and were used for analysis. The four most statistically significant canonical pathways identified by IPA were interferon signalling (Figure 2), complement system (Figure 3), Role of pattern recognition

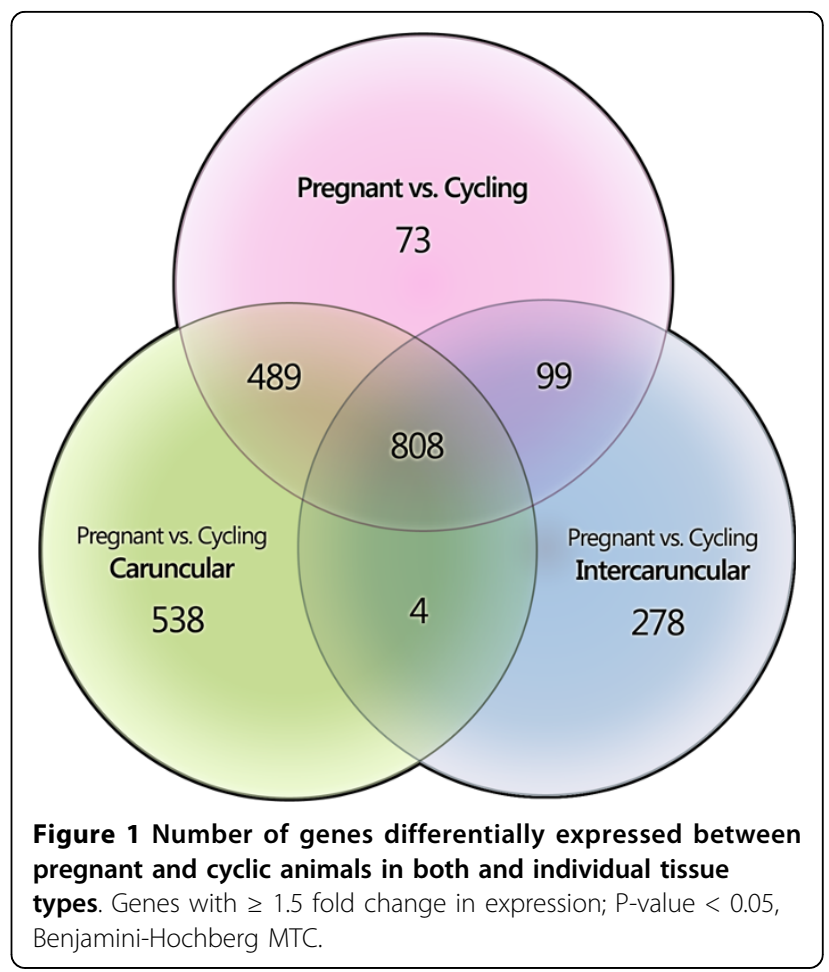

receptors in the recognition of bacteria and viruses, and antigen presentation (Additional file 2, Table S2). The networks generated by IPA that contained the most significant number of genes with direct relationships (molecules that directly affect one another) were:

- Network 1 - Cell death, hematological disease, immunological disease (score $=49,28$ molecules)

- Network 2 - Infection mechanism, antimicrobial response, cell signaling (score $=45,26$ molecules)

- Network 3 - Infectious disease, cell morphology, cellular assembly and organization (score $=43,26$ molecules)

- Network 4 - Cellular growth and proliferation, connective tissue development and function, cell cycle (score $=23,16$ molecules)

- Network 5 - Lipid metabolism, molecular transport, small molecule biochemistry (score $=21,15$ molecules).

'Functional groups' and biological processes associated with pregnancy and estrous cycle progression (cycling animals) in the dairy cow during the preimplantation period were identified. Genes were assigned to molecular and biological functions using the PANTHER (Protein Analysis Through Evolutionary Relationships) classification system (http://www.pantherdb.org/). The biological process "immunity and defence" contained the most genes for this analysis. (Additional file 3, Table S3). 


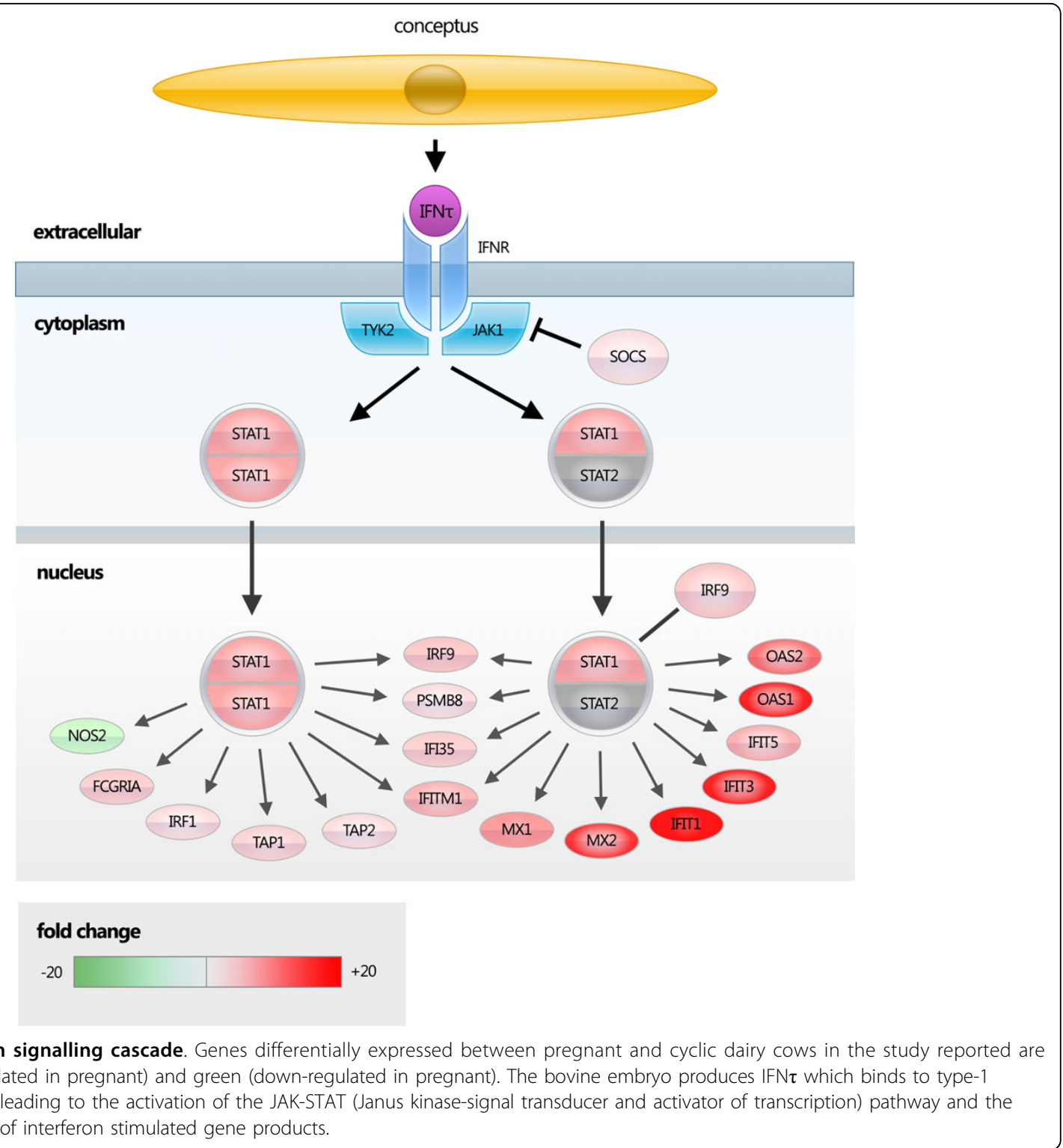

\section{Relative quantitative real time PCR confirmation of microarray results}

Relative qRT-PCR was used to confirm microarray results. 5 genes of interest (OXTR, IDO, SPP1, OAS2, and CXCL11) that were differentially expressed according to microarray analysis were quantified, and the correlation between qRT-PCR and microarray (Pearson correlation coefficient) calculated exceeded 0.75 for all genes tested (Table 1, Figure 4).

\section{Discussion}

\section{Genes up-regulated in pregnant animals}

In this study, endometrial expression profiles of day 17 pregnant and cyclic dairy cows were characterized and several genes and pathways that were differentially expressed between the two states were identified, providing insight into the molecular mechanisms active during this time. Genes and pathways involved in the maternal immune response to the presence of the embryo appear to be particularly important in early pregnancy, as these were some of the most up-regulated genes in pregnant animals. The immune response to pregnancy may be one of the key regulators of pregnancy maintenance, and deregulation of the immune response may be responsible, at least in part, for the large number of pregnancy losses that occur during this time. Both innate and adaptive immune system genes were differentially expressed during early pregnancy. Many genes of the adaptive immune response that were up-regulated may function to induce immune tolerance 


\section{complement system}

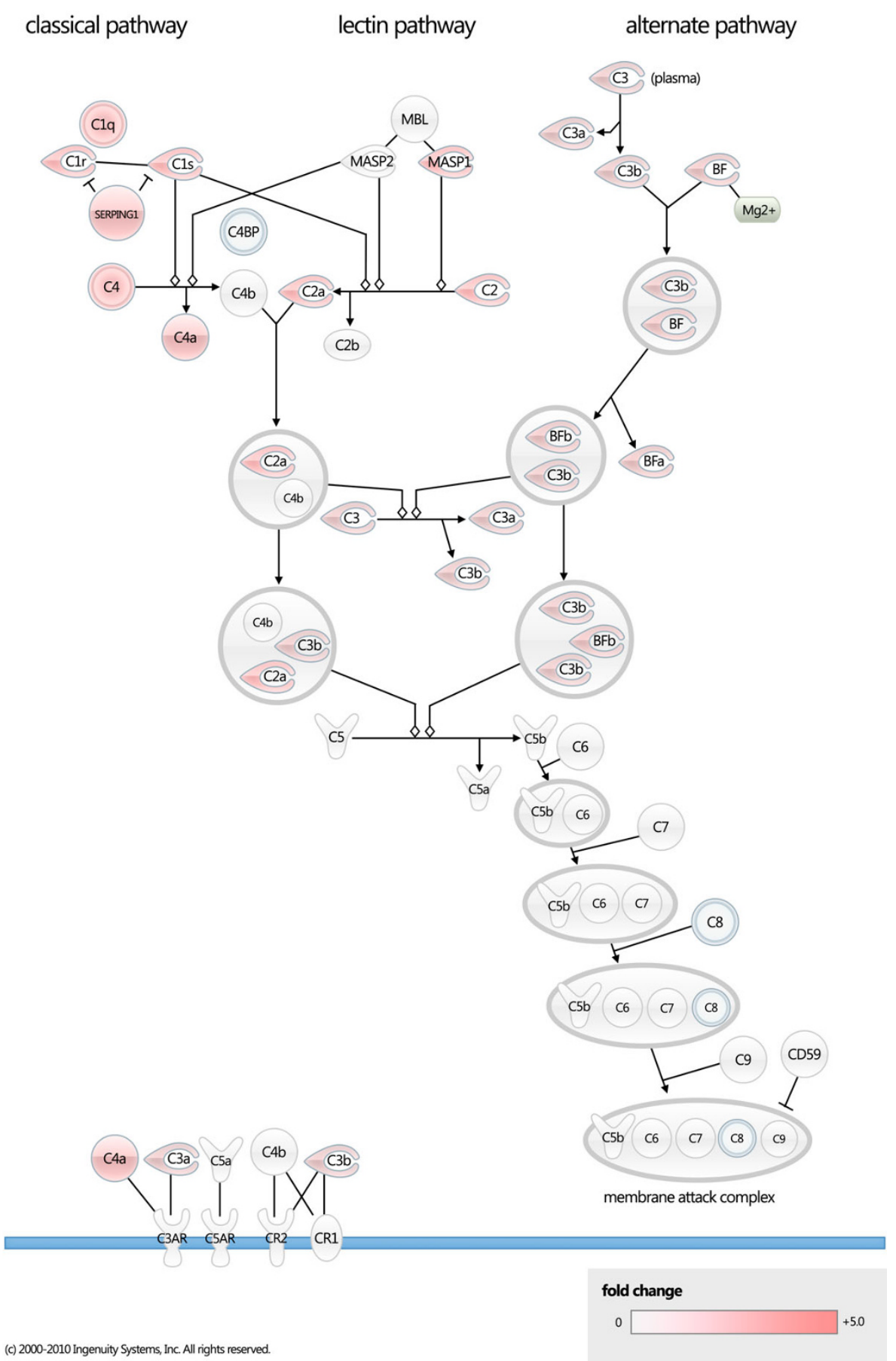

Figure 3 Complement pathway. Genes up-regulated in pregnant dairy cows are shaded red. The complement system is part of the innate immune response and can be activated in three ways: classical pathway, alternative pathway and lectin pathway, all of which converge at the level of C3 convertase. The Classical pathway begins with activation of the $\mathrm{C} 1$ complex $(6 \times \mathrm{C} 1 \mathrm{q}, 2 \times \mathrm{C} 1 \mathrm{r}$ and $2 \times \mathrm{C} 1 \mathrm{~s})$ through the binding of $\mathrm{C} 1 \mathrm{q}$ to antigen bound antibodies (IgG or IgM) or directly to the surface of a pathogen. Binding causes a conformational change in C1q which leads to activation of $\mathrm{C} 1 \mathrm{r}$ and $\mathrm{C} 1 \mathrm{~s}$ (serine proteases), this leads to cleavage of C4 and C2. The cleavage products of C4 and C2 form C3 convertase cleaves $\mathrm{C} 3$, leading to the formation of C5 convertase that cleaves C5 and results in formation of the membrane attack complex [73]. 
Table 1 RT-PCR confirmation of microarray

\begin{tabular}{lllllll}
\hline \multicolumn{2}{l}{ Fold change Pregnant vs Cyclic } & \multicolumn{5}{l}{ Primer Sequences } \\
\hline & Microarray & RT-PCR & Correlation & Forward & Reverse & Probe \\
\hline OXTR & -7.26 & -10.55 & 0.90 & cgtgcagatgtggagtgtct & ttgcagcagctgttgagg & UPL\#162 \\
\hline OAS2 & 10.94 & 31.05 & 0.93 & tggacggtcaactacagtttg & ctgggtccaagatcacagg & UPL\#69 \\
\hline SPP1 & 3.41 & 3.60 & 0.75 & aagttccgccgatctaacg & cctcactctctatgtgtgatgtgaa & UPL\#82 \\
\hline CXCL11 & 5.23 & 6.95 & 0.83 & tgctgcaattgttcaaggtt & tctgccactttgactgctttt & UPL\#81 \\
\hline IDO & 15.25 & 28.97 & 0.76 & acgtaggctttgctcttcca & gagatccaggcatcataagga & UPL\#65 \\
\hline
\end{tabular}

to the embryo, while genes of the innate immune response (in particular, antimicrobial genes) may function to protect the uterus against infection during a time of local immune suppression.

\section{Immune response and interferon signalling}

Interferon stimulated genes (ISG) were among the most up-regulated group of genes in pregnant animals; this is consistent with maximal production of the pregnancy recognition signal interferon tau (IFN $\tau$ ) by the embryo during this time. The most statistically significant networks up-regulated in pregnant animals were involved in the immune response, and immunity and defence were identified as the most abundant gene ontology terms.

Several ISGs were identified as being differentially expressed in pregnant and cyclic animals, in agreement with previous studies [7-11]. The current study, however, has identified several additional ISG not previously identified in the bovine endometrium (Figure 2, Additional file 2, Table S2). Many of these genes may

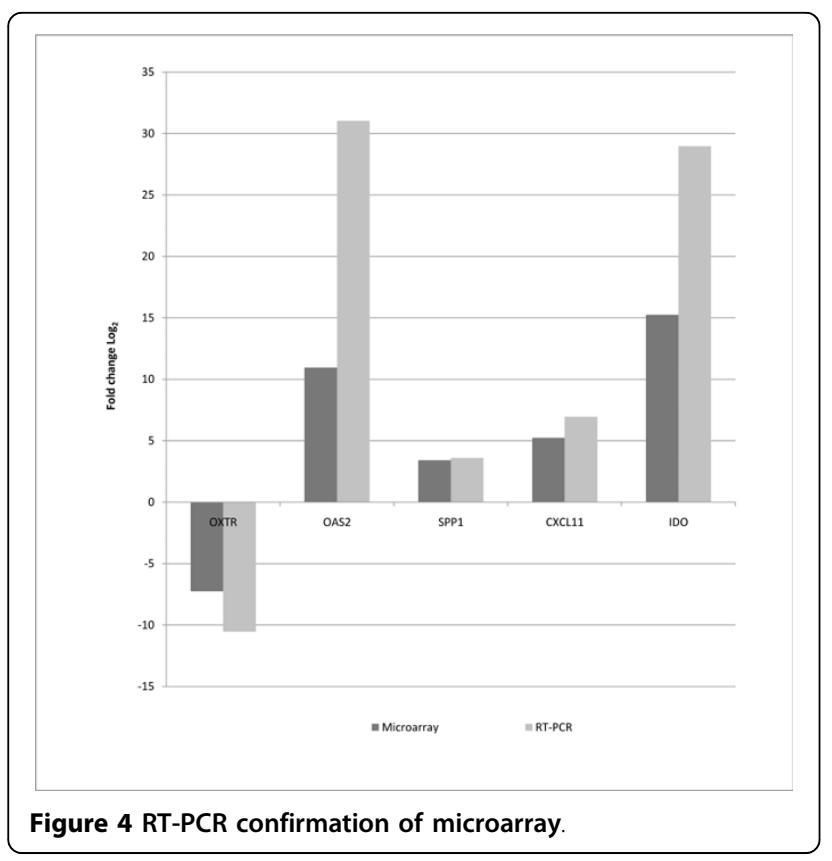

function to provide localized immune system suppression to allow the embryo to survive within the uterus. For example, IFITM1 has recently been demonstrated to act as an immune suppressive molecule in gastric cancer cells [12]. The upregulation of IFITM1 in cancer cells was associated with an increase in migration and invasive capacity, and its action in gastric tumour cells was linked to suppression of NK cells [12]. Peptide Transporter 1 (TAP-1) and TAP-2 were up-regulated in pregnant animals in agreement with another study [13] along with MHC I A, and MHC I G. Upregulation of TAP proteins may be involved in local immune suppression, as upregulation of TAP1 has been associated with the capacity of natural killer cells to be non-cytotoxic [14]. Kalkunte et al 2009 demonstrated that the noncytotoxic phenotype of uNK cells is achieved through the expression of vascular endothelial growth factor- $C$ (VEGF-C), which enhances the resistance of trophoblast and endothelial cells to lysis through induction of the TAP-1 protein [14]. They reported that VEGF-C protected target endothelial and trophoblast cells from cytotoxic NK cells directly through induction of TAP-1.

Additionally, in agreement with a local immune suppression environment, IFIT1, OAS1 and OAS2 are upregulated in the autoimmune disease systemic lupus [15]. OAS upregulation during early pregnancy is also involved in regulating the production of osteopontin (SPP1) [16,17], that was also up-regulated in pregnant animals. Upregulation of SPP1 in pregnant animals may have several functions, including promoting adhesion of the trophoblast to the endometrium, stimulating morphological changes in the trophoblast [18], and regulating the immune response. SPP1 is expressed and secreted by immune cells including T-lymphocytes, monocytes, macrophages and NK cells. SPP1 is presumed to regulate the $\mathrm{TH} 1 / \mathrm{TH} 2$ balance and apoptosis [18]. SPP1 polymorphisms are associated with many immune-mediated inflammatory diseases [19] consistent with a local immune suppressive state. Quantitative trait (QTL) analyses in pigs have identified SPP1 as a candidate gene for reproductive performance [20].

Alternatively, upregulation of these genes may be an important mechanism to enhance the response to 
potential viral pathogens that the uterus may encounter during the time of local immune suppression that occurs in response to the embryo. This Hypothesis is supported by the upregulation of MX1 and MX2, both of which are up-regulated in response to viral infection $[21,22]$. MX2 expression is also up-regulated in peripheral blood leukocytes during pregnancy [23], suggesting the innate immune system is active during early pregnancy.

Several of the above genes are also thought to be important regulators of luteolysis [21]. For example, OAS inhibits prostaglandin F $2 \alpha$ synthesis, possibly through alteration of arachidonic acid metabolism [24]. Interestingly, MX2 expression is lower in the uterus of pregnancies with cloned embryos than in embryos produced by IVF.

\section{Cytokines, chemokines, and growth factors}

Pregnancy requires a delicate balance between proinflammatory and anti-inflammatory molecules to maintain maternal immune system integrity, while preventing rejection of the embryo. Expression patterns of chemokines and their receptors during the implantation period suggest that they are involved in the regulation of embryo attachment as well as having immunomodulatory properties. Chemokines attract leukocytes to sites of inflammation, and contribute to their local activation.

Several chemokines were up-regulated in pregnant animals in agreement with other studies [25-28]. The CXCR3 ligands CXCL9, CXCL10 and CXCL11 were all up-regulated in pregnant animals, a difference that is more pronounced in the caruncular compared with intercaruncular tissue. CXCR3 is preferentially expressed on TH1 cells, and the expression of ligands for this receptor suggests there may be an influx of TH1 cells into the uterus. Upregulation of the CXCR3 receptor ligands and the influx of TH1 cells have been associated with allograft rejection $[25,29]$. However since CXCR3 was not up-regulated, it suggests that either TH1 cell numbers were not increased in the uterus of pregnant animals, or that they were not expressing this receptor. CXCR3 is also expressed in human uterine natural killer cells [30], so upregulation of these chemokines may function to attract the trophoblast and/or uNK cells. Several chemokines that were up-regulated in pregnant animals are known to attract immune tolerance promoting leukocytes, including TH2 and NK cells. For example, CCL11, which was upregulated in both intercaruncular and caruncular tissue in pregnant animals attracts CCR3-expressing TH2 cells [31], and CCL2, which was only upregulated in caruncular tissue, attracts leukocytes expressing its receptor CCR2 [31,32]. Consistent with this is the association of CCL2 upregulation with immune tolerance in endometriosis, a mechanism suggested to act through its action on the
FAS ligand, inducing apoptosis of T lymphocytes [33]. The FAS ligand, along with FAS and the downstream effector molecules FADD and caspase were all upregulated in pregnant animals in both tissue types. Another NK cell attracting chemokine up-regulated in pregnant animals was CCL8 [34]. This chemokines was upregulated 17 fold in the caruncular endometrium, and 9 fold in the intercaruncular endometrium. In addition to attracting NK cells, CCL8 can attract monocytes, lymphocytes, eosinophils, and basophils through its capacity to bind to the CCL2 receptor CCR2 as well as CCR1, CCR3 and CCR5. Both CCR1 and CCR5 were upregulated in caruncular and intercaruncular tissues of pregnant animals. Co-expression of proteases that can convert CCL8 to CCL8(6-75) results in an anti-inflammatory response, as CCL8(6-75) can inhibit other chemokines through its ability to act as a receptor antagonist [35]

Several interleukins that were up-regulated in pregnant animals may function to increase the presence of immune tolerance promoting T-regulatory (T-reg) cells in the uterus, as well as shifting the inflammatory balance towards an anti-inflammatory response. T-reg cells require low levels of some cytokines in order to differentiate from naive CD4+ T cell precursors, with high levels blocking suppression. In particular, IL-15, which was up-regulated 2 fold in the caruncular endometrium of pregnant animals. IL-15 also induces proliferation of T-reg cells [36]. Another cytokine that was up-regulated in the pregnant endometrium, IL-7, is considered a growth and survival promoting factor for $\mathrm{T}$-reg cells [37]. Interleukin $1 \beta$ (IL-1 $\beta$ ) and interleukin 18 (IL-18) are pro-inflammatory cytokines that were up-regulated in pregnant animals. Caspase 1 , which proteolytically cleaves the IL-1 $\beta$ precursor to its active form, was also up-regulated in the caruncular endometrium of pregnant animals. Inhibitors of these cytokines, IL-1RN and IL-18BP were also up-regulated in pregnant animals. IL$1 \mathrm{RN}$ has recently been reported to be up-regulated in the pregnant equine endometrium [38], and down-regulated during the window of implantation in the cyclic human [39].

The TGF $\beta$ superfamily is a large functionally diverse protein family which includes several subfamilies including activins, bone morphogenic proteins (BMPs) and growth differentiation factors (GDF) [40]. Members of this family were differentially regulated with respect to pregnancy in the current study including TGF $\beta 1,2$ and 3 , which were all down-regulated in pregnant animals. The TGF- $\beta$ superfamily members have immunomodulatory/inflammatory actions, some of which may be important during pregnancy recognition and maintenance. However, in the current study TGF $\beta 1,2$, and 3, TGF $\beta 111$, and BMP6 were all down-regulated in 
pregnant animals, while TGF $\beta$ I was up-regulated in pregnant animals in caruncular endometrium. Other members of this family that were down-regulated in pregnancy include; myostatin, Inhibin $\beta$ A and Inhibin $\beta$ $B$, this is coupled with increased expression of follistatin (2.8 fold), an inhibitor of both activins and myostatin. While activins have immunomodulatory actions [41] the GDF, myostatin has been proposed to have a role in glucose metabolism [42] in the placenta [43], and in an endometrial cell line [44]. Myostatin may be an important regulator of glucose availability to the embryo through regulation of glucose in endometrial histotroph secretions, and later for fetal development through regulation of placental glucose transport. Reduced myostatin accompanied by increased follistatin indicates that this pathway is under tight control during early pregnancy.

\section{Antigen presentation and complement related genes}

Complement pathway genes are some of the most commonly up-regulated genes in this and previous studies of endometrial gene expression during the window of implantation [8,45-47]. In particular, several molecules involved in activation of complement via the classical pathway were up-regulated in pregnant animals (Figure 3 ). Upregulation of complement may serve to provide the developing embryo with protection against pathogens and/or immune complexes and apoptotic cells, an important adaptation given the local immune suppressive state necessary for successful embryo implantation and placentation. Molecules that protect against complement mediated cells are expressed in the endometrium and trophoblast [48]. Consistent with this observation, pentraxin 3 (PTX3) was up-regulated in pregnant animals, particularly in the caruncules. PTX3 binding to the $\mathrm{C} 1 \mathrm{q}$ complex can activate or inhibit the classical complement pathway depending on the nature of the interaction $[49,50]$. Upregulation of PTX3 may function to control the complement cascade in the pregnant animal and prevent excessive inflammatory reactions. Another gene that was up-regulated and may function to inhibit complement mediated immune responses is SERPING1. SERPING1 is a progesterone-induced, immunosuppressive and anti-proliferative glycoprotein contained in uterine secretions [51]. SERPING1 can inhibit complement-mediated immune responses through inactivation of C1s. Upregulation of SERPING1 may function to suppress a complement-mediated immune response to fetal antigens, and may also be important for embryonic growth. SERPING1 has been proposed to support conceptus growth through its ability to sequester the pluripotent growth factor activin A. Because of its immunosuppressive and anti-proliferative properties, it has been hypothesized to prevent fetal allograph rejection through inhibition of lymphocyte proliferation in the uterus [51]. Other SERPIN's that were differentially regulated include; SERPINA9, SERPINA1 and SERPINB11.

Other genes that were up-regulated in pregnant tissue encode immunoproteasome subunits PSMB8 and PSMB9, and antigenic peptide transporters TAP1 and TAP2 [52]. These results identify modulation of the extent and specificity of antigen presentation as a mechanism likely required for pregnancy success.

MHC class 1 and class 2 molecules along with B2 M were identified as being up-regulated in pregnant animals. Up-regulation of MHC class 1 and B2 $\mathrm{M}$ in response to pregnancy and interferons has been demonstrated $[53,54]$. Downregulation of classical MHC class 1 molecules in trophoblast tissue is a well characterized mechanism proposed to prevent immunological attack of the embryo [5]. The expression of MHC molecules in uterine tissue during pregnancy is poorly characterised. It has been proposed that upregulation of MHC class 1 molecules and B2 M may compensate for loss of mucin expression in the endometrial luminal epithelium[53]. Mucin-1 (MUC-1) forms part of the glycocalyx barrier that provides innate immune protection against bacterial infections; downregulation of MUC-1 is thought to be required for embryo attachment as the ectoderm tail presents a steric hindrance to attachment [52]. MUC-1 was down-regulated in pregnant animals in the study reported here, suggesting this mechanism may be active in the bovine endometrium also. Furthermore, the nonclassical MHC class 1 molecule HLA-G was up-regulated in pregnant animals, perhaps to support an immunosuppressive action on the maternal immune system.

\section{Antimicrobial response genes}

Several antimicrobial genes are up-regulated in the endometrium of pregnant animals. LBP and BPI, encode proteins that bind bacterial endotoxin. Both were upregulated in pregnant animals, 19 fold and 6 fold respectively, as was the antibacterial gene LYZ1 which was up-regulated 2.4 fold in pregnant animals. Increased expression of these genes in pregnant animals may confer innate immune protection against potential bacterial infection during a time of local immune suppression, as occurs during pregnancy [55].

\section{Other immune response related genes}

Indoleamine -2,3 dioxygenase (IDO) and tryptophanyltRNA synthetase (TTS/WARS) were up-regulated 5.7 fold and 2.4 fold respectively in endometrium of pregnant cows' in the current study. Upregulation of IDO has been reported in other species [56-58] and is likely to have an immunosuppressive function in the cow. Munn et al (1998) described a novel mechanism by which the maternal system prevents fetal rejection through increased IDO expression, specifically through the suppression of T-cell activity. Dendritic cell expression of IDO causes increased catabolism of the essential 
amino acid tryptophan, and increased concentration of the tryptophan metabolites 3-OH-Kynurenine and 3$\mathrm{OH}$-anthranilic acid. Tryptophan catabolism reduces the amount of tryptophan available in the microenvironment for protein synthesis, and can thus prevent expansion of T-cells. In addition, tryptophan metabolites have immunosuppressive properties such that they cause $\mathrm{T}$ cell apoptosis. Cells expressing IDO are protected against tryptophan starvation, possibly through expression of TTS/WARS. TTS is the only known aminoacyltRNA synthetase induced by interferon gamma. The formation of a tryptophan-tRNA complex results in the generation of a reservoir of tryptophan that may function to protect IDO expressing cells from tryptophan depletion. Upregulation of these genes suggests this mechanism is active in the pregnant bovine endometrium and is likely an important contributor to pregnancy success in dairy cattle.

Several galectins were differentially expressed between pregnant and cyclic animals. Galectin 9 was up-regulated 2.8 fold in pregnant cows while galectin 8 and galectin 3 binding protein (caruncular only) were upregulated 1.7 and 2.2 fold respectively. In contrast, galectin 12 was down-regulated in pregnant animals (1.6 fold) compared to cyclic animals. Galectins are a family of lectins that bind to beta-galactoside motifs in ligands such as laminin, fibronectin, and mucins in bivalent or multivalent ways, to modulate cellular adhesion [59]. Galectin 3 binding protein (Lgals3bp) can bind to Galectin $-1,-3$ and -7 , promoting cell-cell adhesion through bridging between galectin molecules bound to ECM components $[60,61]$. It can also self-assemble to form high molecular weight complexes that promote cell adhesion through binding of integrins, collagens and fibronectin independently of Galectin 3 [61]. It has been demonstrated that Galectin-9 administration improves the survival of allogenic skin grafts in mice, possibly through induction of host cytotoxic CD8a+ T cell apoptosis [62]. Galectin-9 inhibits the secretion of TH1 and TH17 type cytokines, and promotes the synthesis of TH2 type cytokines in vitro [63]. Galectin-9 is potentially involved in modulation of the immune system during early pregnancy through its ability to induce apoptosis of immune cells, including activated CD4+ and $\mathrm{CD} 8+\mathrm{T}$ cells through $\mathrm{Ca} 2+$ calpain caspase 1 pathway [64].

Some of the most highly expressed genes in the pregnant animals in this study were guanylate binding proteins (GBP), which belong to a family of GTPases that also includes Mx proteins (up-regulated in pregnant animals). GBPs regulate inhibition of proliferation, invasion of endothelial cells and cell survival. GBPs bind to guanine nucleotides, they contain two binding motifs. GBP1 is up-regulated in the human endometrium during the window of implantation [65], and GBP1 and GBP-3,-4,5 are up-regulated in the bovine endometrium at day 18 of pregnancy [10]. Consistent with this premise, GBP-1,2,-3,-4 and GBP-6-7 were up-regulated in pregnant animals in the current study. GBPs are up-regulated in patients with inflammatory bowel disease (IBD) and also found to be associated with epithelial tight junctions, where downregulation of GBP through siRNA causes an increase in barrier permeability [66]. It has recently been suggested that the functional significance of GBP upregulation is to protect cells against pro-inflammatory cytokine induced apoptosis [66].

\section{Difference in caruncular and intercaruncular endometrial tissue}

The majority of genes differentially expressed between pregnant and cyclic animals are in both caruncular and intercaruncular tissues. However, the magnitude of differential expression between pregnant and cyclic endometrium differs in the two tissues, and there are some genes that are only differentially expressed in one of the two tissue types. The caruncules of the endometrium are specialised projections that are the site of embryo attachment. Caruncules become highly vascularised, and are the major site for small molecule and gaseous exchange[4]. In comparison, intercaruncular tissue is highly glandular and responsible for early nourishment of the embryo through secretions of large molecules into the uterus [67-69]. The magnitude of some of these gene expression changes differs considerably between the two tissue types. RSAD2 is the most differentially expressed gene (23 fold up-regulated in pregnant animals) in the comparison of pregnant versus cyclic animals. In this comparison, RSAD2 is 3 fold more differentially expressed in caruncular than it is in intercaruncular tissue. This difference occurs in most of the genes discussed. The larger difference in gene expression seen in the caruncular tissue (indicating a greater response to pregnancy), may reflect the role of this tissue in implantation. The caruncules, being the site of embryo attachment may demand more extreme gene expression changes that promote tolerance to the embryo, allowing it to form a closer physical relationship without immunological attack.

\section{Conclusion}

The maternal immune system is actively surveying the uterine environment during early pregnancy. The embryo modulates this response, inducing expression of molecules in the endometrium that function to suppress the immune response and/or promote tolerance to the embryo. The current study demonstrates this response with widespread upregulation of immune response pathways. During this period of immune suppression the 
endometrium would be expected to be susceptible to infections; the endometrium must, therefore, actively express specific molecules for defence against foreign pathogens. Upregulation of genes of the innate immune response including antimicrobial response genes support this hypothesis. This system requires intricate control through expression of protective inhibitors in the endometrium, and raises the question of whether the embryo expresses these same inhibitory molecules.

\section{Methods}

Animals

All Procedures were undertaken with the approval of the Ruakura Animal Ethics Committee (Hamilton, New Zealand). The estrus cycles of 22 lactating dairy cows were synchronized and 12 of these received embryo transfer on day 7 of the estrus cycle. Embryos were at the blastocyst stage of development and of grade 1 quality. Animals were slaughtered at day 17 of the reproductive cycle and endometrial tissues (both caruncular and intercaruncular) were sampled. There were 12 pregnant and 10 cyclic animals representing mixed New Zealand and North American ancestry Holstein Friesian dairy cows. Further details, including production data is provided in Meier et al 2009[70].

\section{RNA Extraction}

Tissues were homogenized in Qiagen buffer RLT (QIAGEN GmbH, QIAGEN Strasse 1, 40724 Hilden, Germany) using Fastprep Lysing Matrix D tubes in a FastPrep instrument (MP Biomedicals, 29525 Fountain Pkwy, Solon, OH 44139).

Total RNA was extracted using a Qiagen RNeasy kit (Qiagen). RNA quantity was determined by spectrophotometry using a Nanodrop ND-1000 (Nanodrop Technologies, Wilmington, DE). RNA integrity was assessed with the Agilent 2100 Bioanalyzer with a RNA 6000 Nano LabChip kit (Agilent Technologies, Palo Alto, CA).

\section{Microarray}

One $\mu \mathrm{g}$ of RNA was amplified using the amino Allyl MessageAmp ${ }^{\mathrm{Tm}}$ aRNA Kit (Ambion, 2130 Woodward St, Austin TX, 78744) to generate amino allyl modified aRNA for use in microarray hybridization. The aRNA quantity was measured by spectrophotometry using a ND-1000 (Nanodrop Technologies, Wilmington, DE).

Five $\mu \mathrm{g}$ of aRNA was then vacuum dried and labeled with Cy3 and Cy5 NHS ester (Amersham Cy3 and Cy5 Mono-Reactive Dye Packs, GE Healthcare UK Ltd., Little Chalfont, Buckinghamshire). Labeled aRNA was then purified on column. Labeling efficiency was determined by spectrophotometry using the Nanodrop 1000 .

$825 \mathrm{ng}$ of $\mathrm{Cy} 3$ and $\mathrm{Cy} 5$ labeled and fragmented aRNA were added to Agilent $44 \mathrm{k}$ 60-mer oligonucleotide microarrays (G2514F), hybridized overnight (17 hours), washed and air dried according to the manufacturer's instructions (Agilent Gene Expression Hybridization Kit 60-mer oligo microarray protocol version 4.0). Arrays were scanned using the Agilent DNA microarray scanner.

\section{Hybridization design}

A total of 44 microarrays were used in this study, one for each tissue type of the 22 animals. A reference sample was utilized, made from equal amounts of RNA from each endometrial sample analyzed (22 caruncular and 22 intercaruncular samples). This pooled sample was used as a 'reference' in each array hybridization. The reference sample was labeled with the Cy3 NHS ester dye, while each individual sample was labeled with the Cy5 NHS ester dye.

\section{Data analysis and statistics}

Agilent feature extraction software version 7.1 was used to analyse the scanned Agilent microarray. The 44 scanned microarray image files were uploaded to the feature extraction software. Using a design file (015354), the feature extraction software locates features and converts the extracted data from each feature into a quantitative $\log$ ratio. The software removes pixel outliers, performs statistical tests on the non outlier pixels, subtracts background from features and flags any outlier features. The software was then used to perform a LOWESS (locally weighted linear regression analysis) dye normalisation and to calculate a p-value for each feature.

Data analysis was performed with Genespring GX 7.3.1. (Agilent, Palo Alto, CA, USA). Microarray data were imported into Genespring using Agilent's twocolor 'Enhanced FE' import scenario which included 'Per Spot: Divide by control channel' and 'Per Chip: Normalize to 50th percentile' normalization steps.

Filters applied to the data to improve the quality of the normalized dataset included; firstly, filtering 'on flags' to ensure any probes that were not deemed 'present or marginal' (according to feature extraction spot quality guidelines) in at least 22 of the 44 arrays were omitted from analysis; secondly, probes that did not have a minimum threshold of 80 raw intensity units in at least 22 of 44 arrays were also omitted from analysis $(15,833$ probes passed this filter). The raw intensity cut off value of 80 was determined based on the base over proportional $(C=a / b)$ calculation, which is generated by plotting the standard deviation of normalized values against the control values. The point at which the curve flattens out is where the data measurement becomes reliable or where $C$ (control strength) $=\mathrm{a} / \mathrm{b}$ (where $\mathrm{a}=$ base and $b=$ the proportional coefficient). 
Differentially expressed probes were identified using a T-Test, including a Benjamini-Hochberg false discovery rate multiple testing correction (MTC). For probes that were not annotated, full length transcripts were identified where possible by querying microarray probe sequences against the bovine genome (Btau3,1) using NCBI BLAST (http://blast.ncbi.nlm.nih.gov/Blast.cgi). Microarray data was submitted to NCBI gene expression omnibus (GSE19140).

\section{CDNA Synthesis}

One $\mu \mathrm{g}$ of an RNA sample was used for cDNA synthesis using the Invitrogen Superscript III Supermix kit (Invitrogen, Carlsbad, California, USA). Total RNA was transcribed according to the manufacturer's instructions using $27 \mu \mathrm{M}$ of random pentadecamers. Briefly, RNA and random primers were mixed and denatured at $65^{\circ} \mathrm{C}$ for 5 minutes, followed by 1 minute on ice. Annealing buffer and Superscript/RNase was added to samples and incubated for 10 minutes at $25^{\circ} \mathrm{C}$ (primer annealing), followed by 50 minutes at $50^{\circ} \mathrm{C}$ and 5 minutes at $85^{\circ} \mathrm{C}$ to inactivate the enzyme. Reverse transcription controls were performed, whereby the above process was completed without the addition of superscript enzyme.

\section{Quantitative Real Time PCR}

Real time PCR using the Roche Lightcycler 480 was performed using the Roche real time PCR master mix (Lightcycler 480 Probes Master) in combination with Roche Universal Probe Library (UPL) assays (Roche diagnostics, Indianapolis, IN, USA). Assays were designed using Roche UPL design software. All assays were designed to span an intron-exon boundary.

The PCR reaction volume was $10 \mu \mathrm{L}$, consisting of 0.5 $\mu \mathrm{M}$ of each primer and $0.1 \mu \mathrm{M}$ of probe. Standard cycling conditions were used $\left[95^{\circ} \mathrm{C}\right.$ for 10 minutes, $\left(95^{\circ} \mathrm{C}\right.$ for 10 seconds, $60^{\circ} \mathrm{C}$ for 30 seconds $) \times 50$ cycles, $40^{\circ} \mathrm{C}$ for 40 seconds].

Each PCR experiment included a reaction in which template was replaced by water, and a reaction omitting reverse transcriptase as controls. Triplicate measurements were performed for all samples and standard curves. The percent coefficient of variation (\%CV) for Cps was calculated for each sample. All samples for each gene were run on the same plate.

\section{Absolute quantification}

The Roche Lightcycler 480 software was used to perform absolute quantification analysis of gene expression using the standard curve second derivative maximum analysis method, which is a non-linear regression line method. A six point standard curve was used with a starting concentration of 1 and final concentration of 1.6E-03.

\section{Relative quantification}

The Roche Lightcycler 480 Software was used to perform quantification using the 'advanced relative quantification analysis' algorithm. Two endogenous control genes were used to normalize the data, taking the geometric mean of the normalized ratio of target gene to each reference gene [71]. A calibrator sample was then used as a control, whereby each calculated expression value was normalized to the calibrator sample.

The RT-PCR results were compared to those obtained using the microarray for five differentially expressed genes (OXTR, IDO, SPP1, OAS2, and CXCL11). Correlation coefficients were calculated for all genes to compare the calculated gene expression data from qRT-PCR and the microarray data. Genes for RT-PCR were selected based on two criteria. Biological significance and fold change.

\section{Gene function and pathway identification}

Differentially regulated genes were annotated with biological and molecular functions using the PANTHER (Protein ANalysis THrough Evolutionary Relationships) Classification System (http://www.pantherdb.org/) [72]. Ingenuity pathway analysis (IPA - Ingenuity ${ }^{\oplus}$ Systems, http://www.ingenuity.com) was used for biological network generation and functional analysis.

Gene lists containing differentially expressed genes for each comparison (pregnant versus cyclic, caruncular pregnant versus caruncular cyclic, and intercaruncular pregnant versus intercaruncular cyclic, 1.5 fold differential expression, P-value $\leq 0.5$, Benjamini-Hochberg FDR MTC) were used for analyses. The human homologue corresponding to the bovine gene representing each transcript identified as being differentially expressed was used.

For Ingenuity pathway analysis, the above gene list was uploaded and a core analysis was performed. The default background (ingenuity knowledge base) was used for all analyses. Each gene in the uploaded list was assessed for network eligibility (determined by the representation of the gene in the Ingenuity pathway knowledge base). Each eligible gene was then mapped using the data contained within the Ingenuity knowledge base. Networks were generated based on connectivity of each of the genes, and a score ( $p$-value calculation) was assigned based on likelihood that these genes are part of a network and did not associate due to random chance. This score was then used to rank each of the generated networks. Molecules that are known to have direct and indirect associations were used for network generation.

IPA was also used to identify significant 'biological functions'. A Fischer's exact test was used to calculate the probability that the assigned biological function was not due to random chance. 
Canonical pathways contained within the IPA database were used to identify pathways that were significantly enriched in the dataset. The ratio of genes associated with each canonical pathway to the total number of genes in that pathway was calculated, and a Fisher's exact test was used to test the probability that the association of these genes was significant.

\section{Additional material}

\section{Additional file 1: Table S1: List of differentially expressed genes between pregnant and cyclic animals ( $\geq 1.5$ fold change in expression; P-value < 0.05, Benjamini-Hochberg MTC).}

Additional file 2: Table S2: Top canonical pathways identified using IPA. *Interferon stimulated genes not previously identified in the bovine endometrium.

Additional file 3: Table S3: Genes identified as relating to immunity and defence through PANTHER analysis

\begin{abstract}
Acknowledgements
This work was supported by funding from New Zealand Dairy Farmers through DairyNZ Inc. (New Zealand; Project AN708), and the Foundation for Research, Science, and Technology (New Zealand, DRCX 0301 and

DRCX0202). The authors acknowledge the statistical advice and assistance of Barbara Dow. The authors acknowledge Steve Davis and Chris Burke for their critical analysis of the manuscript and Steve Salmond for the pathway artwork.

\section{Author details}

'DairyNZ Ltd., Hamilton, New Zealand. ${ }^{2}$ Liggins Institute, The University of Auckland, Grafton, New Zealand. ${ }^{3}$ ViaLactia Biosciences, Auckland, New Zealand. ${ }^{4}$ UQ Centre for Clinical Research, The University of Queensland, Brisbane, Queensland.
\end{abstract}

\section{Authors' contributions}

CGW was involved in experimental design, performed the experimental work and statistical analysis, and drafted the manuscript. SM designed the animal trial, carried out sample collection, acted as project manager and obtained funding for the project. MDL was involved in experimental design, critical analysis of the manuscript, and general supervision of the project. $\mathrm{KL}$ designed the microarrays and was involved in critical analysis of the manuscript. JRR was involved in critical analysis of the manuscript and general supervision of the project. MDM was involved in experimental design, critical analysis of the manuscript and general supervision of the project. All Authors read and approved the final manuscript.

Received: 6 May 2010 Accepted: 13 August 2010

Published: 13 August 2010

\section{References}

1. Garnsworthy PC, Sinclair KD, Webb R: Integration of Physiological Mechanisms That Influence Fertility in Dairy Cows. animal 2008, 2:1144-1152

2. Diskin MG, Murphy JJ, Sreenan JM: Embryo survival in dairy cows managed under pastoral conditions. Animal Reproduction Science 2006 96:297-311.

3. Wolf E, Arnold GJ, Bauersachs S, Beier HM, Blum H, Einspanier R, Fröhlich T, Herrler A, Hiendleder S, Kölle $S$, et al: Embryo-maternal communication in bovine - strategies for deciphering a complex cross-talk. Reproduction in Domestic Animals = Zuchthygiene 2003, 38:276-289.

4. Atkinson BA, King GJ, Amoroso EC: Development of the caruncular and intercaruncular regions in the bovine endometrium. Biol Reprod 1984, 30:763-774.
5. Bainbridge DR: Evolution of mammalian pregnancy in the presence of the maternal immune system. Rev Reprod 2000, 5:67-74.

6. Medawar P: Some immunological and endocrinological problems raised by the evolution of viviparity in vertebrates. Symposia of the Society for Experimental Biology 1953, 7:320-338.

7. Bauersachs S, Ulbrich SE, Gross K, Schmidt SEM, Meyer HHD, Einspanier R, Wenigerkind $\mathrm{H}$, Vermehren M, Blum H, Sinowatz F, Wolf E: Gene expression profiling of bovine endometrium during the oestrous cycle: detection of molecular pathways involved in functional changes. $J \mathrm{Mol}$ Endocrinol 2005, 34:889-908.

8. Bauersachs S, Ulbrich SE, Gross K, Schmidt SEM, Meyer HHD, Wenigerkind H, Vermehren $M$, Sinowatz F, Blum $H$, Wolf E: Embryo-induced transcriptome changes in bovine endometrium reveal species-specific and common molecular markers of uterine receptivity. Reproduction 2006, 132:319-331.

9. Mitko K, Ulbrich SE, Wenigerkind $H$, Sinowatz F, Blum H, Wolf $E$, Bauersachs S: Dynamic changes in messenger RNA profiles of bovine endometrium during the oestrous cycle. Reproduction 2008, 135:225-240.

10. Klein $C$, Bauersachs $S$, Ulbrich SE, Einspanier R, Meyer HHD, Schmidt SEM, Reichenbach H-D, Vermehren M, Sinowatz F, Blum H, Wolf E: Monozygotic Twin Model Reveals Novel Embryo-Induced Transcriptome Changes of Bovine Endometrium in the Preattachment Period. Biol Reprod 2006, 74:253-264.

11. Mansouri-Attia N, Sandra O, Aubert J, Degrelle S, Everts RE, GiraudDelville C, Heyman Y, Galio L, Hue I, Yang X, et al: Endometrium as an early sensor of in vitro embryo manipulation technologies. Proceedings of the National Academy of Sciences 2009, 106:5687-5692.

12. Yang $Y$, Lee J-H, Kim KY, Song HK, Kim JK, Yoon SR, Cho D, Song KS, Lee $\mathrm{YH}$, Choi I: The interferon-inducible 9-27 gene modulates the susceptibility to natural killer cells and the invasiveness of gastric cancer cells. Cancer Letters 2005, 221:191-200.

13. Popovici RM, Betzler NK, Krause MS, Luo M, Jauckus J, Germeyer A, Bloethner S, Schlotterer A, Kumar R, Strowitzki T, von Wolff M: Gene Expression Profiling of Human Endometrial-Trophoblast Interaction in a Coculture Model. Endocrinology 2006, 147:5662-5675.

14. Kalkunte SS, Mselle TF, Norris WE, Wira CR, Sentman CL, Sharma S: Vascular Endothelial Growth Factor C Facilitates Immune Tolerance and Endovascular Activity of Human Uterine NK Cells at the Maternal-Fetal Interface. J Immunol 2009, 182:4085-4092.

15. Ye S, Pang H, Gu YY, Hua J, Chen XG, Bao CD, Wang Y, Zhang W, Qian J, Tsao BP, et al: Protein interaction for an interferon-inducible systemic lupus associated gene, IFIT1. Rheumatology 2003, 42:1155-1163.

16. Spencer TE, Gray A, Johnson GA, Taylor KM, Gertler A, Gootwine E, Ott TL, Bazer FW: Effects of Recombinant Ovine Interferon Tau, Placental Lactogen, and Growth Hormone on the Ovine Uterus. Biol Reprod 1999, 61:1409-1418.

17. McAveney KM, Book ML, Ling P, Chebath J, Yu-Lee L-y: Association of 2',5'Oligoadenylate Synthetase with the Prolactin (PRL) Receptor: Alteration in PRL-Inducible Stat1 (Signal Transducer and Activator of Transcription 1) Signaling to the IRF-1 (Interferon-Regulatory Factor 1) Promoter. $\mathrm{Mol}$ Endocrinol 2000, 14:295-306.

18. Johnson GA, Burghardt RC, Bazer FW, Spencer TE: Osteopontin: roles in implantation and placentation. Biology of Reproduction 2003, 69:1458-1471.

19. Johnson GA, Spencer TE, Burghardt RC, Taylor KM, Gray CA, Bazer FW: Progesterone modulation of osteopontin gene expression in the ovine uterus. Biology of Reproduction 2000, 62:1315-1321.

20. King $A H$, Jiang Z, Gibson JP, Haley CS, Archibald AL: Mapping quantitative trait loci affecting female reproductive traits on porcine chromosome 8 . Biology of Reproduction 2003, 68:2172-2179.

21. Hicks BA, Etter SJ, Carnahan KG, Joyce MM, Assiri AA, Carling SJ, Kodali K, Johnson GA, Hansen TR, Mirando MA, et al: Expression of the uterine Mx protein in cyclic and pregnant cows, gilts, and mares. J Anim Sci 2003, 81:1552-1561.

22. Bauersachs S, Ulbrich SE, Zakhartchenko V, Minten M, Reichenbach M, Reichenbach H-D, Blum H, Spencer TE, Wolf E: The endometrium responds differently to cloned versus fertilized embryos. Proceedings of the National Academy of Sciences 2009, 106:5681-5686.

23. Gifford CA, Racicot K, Clark DS, Austin KJ, Hansen TR, Lucy MC, Davies CJ, Ott TL: Regulation of Interferon-Stimulated Genes in Peripheral Blood Leukocytes in Pregnant and Bred, Nonpregnant Dairy Cows. J Dairy Sci 2007, 90:274-280. 
24. Schmitt RA, Geisert RD, Zavy MT, Short EC, Blair RM: Uterine cellular changes in 2',5'-oligoadenylate synthetase during the bovine estrous cycle and early pregnancy. Biol Reprod 1993, 48:460-466.

25. Cox JH, Dean RA, Roberts CR, Overall CM: Matrix metalloproteinase processing of CXCL11//-TAC results in loss of chemoattractant activity and altered glycosaminoglycan binding. The Journal of Biological Chemistry 2008, 283:19389-19399.

26. Li B, Xu W, Xu L, Jiang Z, Wen Z, Li K, Xiong S: I-TAC is a dominant chemokine in controlling skin intragraft inflammation via recruiting CXCR3+ cells into the graft. Cellular Immunology, Corrected Proof.

27. Hirota Y, Osuga Y, Koga K, Yoshino O, Hirata T, Morimoto C, Harada M, Takemura $Y$, Nose $E$, Yano $T$, et al: The expression and possible roles of chemokine CXCL11 and its receptor CXCR3 in the human endometrium. Journal of Immunology (Baltimore, Md: 1950) 2006, 177:8813-8821.

28. Imakawa K, Imai M, Sakai A, Suzuki M, Nagaoka K, Sakai S, Lee S-R, Chang KT, Echternkamp SE, Christenson RK: Regulation of conceptus adhesion by endometrial CXC chemokines during the implantation period in sheep. Molecular Reproduction and Development 2006, 73:850-858.

29. Li B, Xu W, Xu L, Jiang Z, Wen Z, Li K, Xiong S: I-TAC is a dominant chemokine in controlling skin intragraft inflammation via recruiting CXCR3(+) cells into the graft. Cellular Immunology 2010, 260:83-91.

30. Sentman CL, Meadows SK, Wira CR, Eriksson M: Recruitment of uterine NK cells: induction of CXC chemokine ligands 10 and 11 in human endometrium by estradiol and progesterone. Journal of Immunology (Baltimore, Md: 1950) 2004, 173:6760-6766.

31. Dominguez F, Galan A, Martin JJL, Remohi J, Pellicer A, Simón C: Hormonal and embryonic regulation of chemokine receptors CXCR1, CXCR4, CCR5 and CCR2B in the human endometrium and the human blastocyst. Molecular Human Reproduction 2003, 9:189-198.

32. Meter RA, Wira CR, Fahey JV: Secretion of monocyte chemotactic protein1 by human uterine epithelium directs monocyte migration in culture. Fertility and Sterility 2005, 84:191-201.

33. Selam B, Kayisli UA, Akbas GE, Basar M, Arici A: Regulation of FAS ligand expression by chemokine ligand 2 in human endometrial cells. Biology of Reproduction 2006, 75:203-209.

34. Hannan NJ, Salamonsen LA: Role of chemokines in the endometrium and in embryo implantation. Current Opinion in Obstetrics \& Gynecology 2007, 19:266-272.

35. Struyf S, Proost P, Vandercappellen J, Dempe S, Noyens B, Nelissen S, Gouwy M, Locati M, Opdenakker G, Dinsart C, Van Damme J: Synergistic up-regulation of MCP-2/CCL8 activity is counteracted by chemokine cleavage, limiting its inflammatory and anti-tumoral effects. European Journal of Immunology 2009, 39:843-857.

36. Guerin LR, Prins JR, Robertson SA: Regulatory T-cells and immune tolerance in pregnancy: a new target for infertility treatment? Hum Reprod Update 2009, 15:517-535.

37. Harnaha J, Machen J, Wright M, Lakomy R, Styche A, Trucco M, Makaroun S, Giannoukakis N: Interleukin-7 is a survival factor for CD4+ CD25+ T-cells and is expressed by diabetes-suppressive dendritic cells. Diabetes 2006, 55:158-170.

38. Haneda S, Nagaoka K, Nambo Y, Kikuchi M, Nakano Y, Matsui M, Miyake Y, Macleod JN, Imakawa K: Interleukin-1 receptor antagonist expression in the equine endometrium during the peri-implantation period. Domestic Animal Endocrinology 2009, 36:209-218.

39. Boucher A, Kharfi A, Al-Akoum M, Bossù P, Akoum A: Cycle-dependent expression of interleukin-1 receptor type II in the human endometrium. Biology of Reproduction 2001, 65:890-898.

40. Jones RL, Stoikos C, Findlay JK, Salamonsen LA: TGF-\{beta\} superfamily expression and actions in the endometrium and placenta. Reproduction 2006, 132:217-232

41. Phillips DJ, de Kretser DM, Hedger MP: Activin and related proteins in inflammation: Not just interested bystanders. Cytokine \& Growth Factor Reviews 2009, 20:153-164.

42. MCPherron AC, Lee S-J: Suppression of body fat accumulation in myostatin-deficient mice. The Journal of Clinical Investigation 2002, 109:595-601.

43. Mitchell MD, Osepchook CC, Leung K-C, McMahon CD, Bass JJ: Myostatin Is a Human Placental Product That Regulates Glucose Uptake. J Clin Endocrinol Metab 2006, 91:1434-1437.
44. Antony N, Bass JJ, McMahon CD, Mitchell MD: Myostatin regulates glucose uptake in BeWo cells. Am J Physiol Endocrinol Metab 2007, 293:E1296-1302, E1296-1302.

45. Lobo SC, Huang STJ, Germeyer A, Dosiou C, Vo KC, Tulac S, Nayak NR, Giudice LC: The Immune Environment in Human Endometrium during the Window of Implantation. American Journal Of Reproductive Immunology 2004, 52:244-251.

46. Gray CA, Abbey CA, Beremand PD, Choi Y, Farmer $J$, Adelson DL, Thomas TL, Bazer FW, Spencer TE: The Immune Environment in Human Endometrium during the Window of Implantation. Biol Reprod 2006, 74:383-394.

47. Nogawa Fonzar-Marana RR, Ferriani RA, Soares SG, Cavalcante-Neto FF, Teixeira JE, Barbosa JE: Expression of complement system regulatory molecules in the endometrium of normal ovulatory and hyperstimulated women correlate with menstrual cycle phase. Fertility and Sterility 2006, 86:758-761.

48. Francis J, Rai R, Sebire NJ, El-Gaddal S, Fernandes MS, Jindal P, Lokugamage A, Regan L, Brosens JJ: Impaired expression of endometrial differentiation markers and complement regulatory proteins in patients with recurrent pregnancy loss associated with antiphospholipid syndrome. Molecular Human Reproduction 2006, 12:435-442.

49. Nauta AJ, Bottazzi B, Mantovani A, Salvatori G, Kishore U, Schwaeble Wilhelm J, Gingras Alexandre R, Tzima S, Vivanco F, Egido J, et al: Biochemical and functional characterization of the interaction between pentraxin 3 and C1q. European Journal of Immunology 2003, 33:465-473.

50. Popovici RM, Krause MS, Jauckus J, Germeyer A, Brum IS, Garlanda C, Strowitzki T, von Wolff M: The Long Pentraxin PTX3 in Human Endometrium: Regulation by Steroids and Trophoblast Products. Endocrinology 2008, 149:1136-1143.

51. Tekin E, Padua MB, Brad AM, Hansen PJ: Antiproliferative Actions of Ovine Uterine Serpin. American Journal Of Reproductive Immunology 2005, 53:136-143.

52. Achache $H$, Revel $A$ : Endometrial receptivity markers, the journey to successful embryo implantation. Hum Reprod Update 2006, 12:731-746.

53. Joyce MM, Burghardt JR, Burghardt RC, Hooper RN, Bazer FW, Johnson GA: Uterine MHC Class I Molecules and \{beta\}2-Microglobulin Are Regulated by Progesterone and Conceptus Interferons during Pig Pregnancy. J Immunol 2008, 181:2494-2505.

54. Choi Y, Johnson GA, Spencer TE, Bazer FW: Pregnancy and interferon tau regulate major histocompatibility complex class I and beta2microglobulin expression in the ovine uterus. Biology of Reproduction 2003, 68:1703-1710.

55. Weiss J: Bactericidal/permeability-increasing protein (BPI) and lipopolysaccharide-binding protein (LBP): structure, function and regulation in host defence against Gram-negative bacteria. Biochemical Society Transactions 2003, 31:785-790.

56. Drenzek JG, Breburda EE, Burleigh DW, Bondarenko Gl, Grendell RL, Golos TG: Expression of indoleamine 2,3-dioxygenase in the rhesus monkey and common marmoset. Journal of Reproductive Immunology 2008, 78:125-133.

57. Jeddi-Tehrani M, Abbasi N, Dokouhaki P, Ghasemi J, Rezania S, Ostadkarampour M, Rabbani H, Akhondi MA, Fard ZT, Zarnani AH: Indoleamine 2,3-dioxygenase is expressed in the endometrium of cycling mice throughout the oestrous cycle. Journal of Reproductive Immunology 2009, 80:41-48.

58. von Rango U, Krusche CA, Beier HM, Classen-Linke I: Indoleaminedioxygenase is expressed in human decidua at the time maternal tolerance is established. Journal of Reproductive Immunology 2007, 74:34-45.

59. Elola M, Wolfenstein-Todel C, Troncoso M, Vasta G, Rabinovich G: Galectins: matricellular glycan-binding proteins linking cell adhesion, migration, and survival. Cellular and Molecular Life Sciences (CMLS) 2007, 64:1679-1700.

60. Inohara H, Akahani S, Koths K, Raz A: Interactions between Galectin-3 and Mac-2-Binding Protein Mediate Cell-Cell Adhesion. Cancer Res 1996, 56:4530-4534.

61. Sasaki T, Brakebusch C, Engel J, Timpl R: Mac-2 binding protein is a celladhesive protein of the extracellular matrix which self-assembles into ring-like structures and binds beta1 integrins, collagens and fibronectin. The EMBO Journal 1998, 17:1606-1613, 1606-1613. 
62. Wang F, He W, Yuan J, Wu K, Zhou H, Zhang W, Chen ZK: Activation of Tim-3-Galectin-9 pathway improves survival of fully allogeneic skin grafts. Transplant Immunology 2008, 19:12-19.

63. Rabinovich GA, Toscano MA: Turning 'sweet' on immunity: galectinglycan interactions in immune tolerance and inflammation. Nat Rev Immunol 2009, 9:338-352.

64. Kashio Y, Nakamura K, Abedin MJ, Seki M, Nishi N, Yoshida N, Nakamura T, Hirashima M: Galectin-9 Induces Apoptosis Through the Calcium-CalpainCaspase-1 Pathway. J Immunol 2003, 170:3631-3636.

65. Kumar S, Zhu L-J, Polihronis M, Cameron ST, Baird DT, Schatz F, Dua A, Ying Y-K, Bagchi MK, Bagchi IC: Progesterone Induces Calcitonin Gene Expression in Human Endometrium within the Putative Window of Implantation. J Clin Endocrinol Metab 1998, 83:4443-4450.

66. Schnoor M, Betanzos A, Weber DA, Parkos CA: Guanylate-binding protein1 is expressed at tight junctions of intestinal epithelial cells in response to interferon-[gamma] and regulates barrier function through effects on apoptosis. Mucosal Immunol 2008, 2:33-42.

67. Atkinson BA, King GJ, Amoroso EC: Development of the caruncular and intercaruncular regions in the bovine endometrium. Biol Reprod 1984, 30:763-774.

68. Dhaliwal GS, Murray RD, Rees EM, Howard CV, Beech DJ: Quantitative unbiased estimates of endometrial gland surface area and volume in cycling cows and heifers. Research in Veterinary Science 2002, 73:259-265.

69. Asselin E, Drolet P, Fortier MA: In Vitro Response to Oxytocin and Interferon-Tau in Bovine Endometrial Cells from Caruncular and InterCaruncular Areas. Biol Reprod 1998, 59:241-247.

70. Meier S, Peterson AJ, Mitchell MD, Littlejohn M, Walker CG, Roche JR: Genetic strain and reproductive status affect endometrial fatty acid concentrations. J Dairy Sci 2009, 92:3723-3730.

71. Walker C, Meier S, Mitchell M, Roche J, Littlejohn M: Evaluation of real-time PCR endogenous control genes for analysis of gene expression in bovine endometrium. BMC Molecular Biology 2009, 10:100-100.

72. Thomas PD, Campbell MJ, Kejariwal A, Mi H, Karlak B, Daverman R, Diemer K, Muruganujan A, Narechania A: PANTHER: a library of protein families and subfamilies indexed by function. Genome Research 2003, 13:2129-2141.

73. Duncan RC, Wijeyewickrema LC, Pike RN: The initiating proteases of the complement system: Controlling the cleavage. Biochimie 2008, 90:387-395.

doi:10.1186/1471-2164-11-474

Cite this article as: Walker et al:: Modulation of the maternal immune system by the pre-implantation embryo. BMC Genomics 2010 11:474.

\section{Submit your next manuscript to BioMed Central and take full advantage of:}

- Convenient online submission

- Thorough peer review

- No space constraints or color figure charges

- Immediate publication on acceptance

- Inclusion in PubMed, CAS, Scopus and Google Scholar

- Research which is freely available for redistribution 